This item was submitted to Loughborough's Research Repository by the author.

Items in Figshare are protected by copyright, with all rights reserved, unless otherwise indicated.

\title{
Digital design sketching using the tablet PC
}

PLEASE CITE THE PUBLISHED VERSION

http://dx.doi.org/10.1080/14606925.2016.1196091

\section{PUBLISHER}

(c) Taylor \& Francis

\section{VERSION}

AM (Accepted Manuscript)

\section{PUBLISHER STATEMENT}

This work is made available according to the conditions of the Creative Commons Attribution-NonCommercialNoDerivatives 4.0 International (CC BY-NC-ND 4.0) licence. Full details of this licence are available at: https://creativecommons.org/licenses/by-nc-nd/4.0/

\section{LICENCE}

CC BY-NC-ND 4.0

\section{REPOSITORY RECORD}

Evans, Mark, and Noor N. Aldoy. 2019. "Digital Design Sketching Using the Tablet PC". figshare. https://hdl.handle.net/2134/19006. 


\section{Accepted for publication in The Design Journal}

\section{DIGITAL SKETCHING USING THE TABLET PC}

Mark Evans, Loughborough University, UK and Noor Aldoy, Lancaster University, UK

\section{ABSTRACT}

As digital sketching continues to emerge as an alternative to paper-based techniques, a qualitative, triangulated longitudinal study of 9 months duration was undertaken to explore the capabilities of the tablet Personal Computer (PC) to support portable sketching during industrial/product design activity. The methodology involved the unrestricted use of tablet PCs by 16 final year undergraduate industrial/product design students for an entire academic year, with data collection through a sketching exercise (participant and expert questionnaires), design exercise (questionnaire), focus group (coding and clustering) and final questionnaire. The conclusions indicate that the tablet PC represents a significant development in the support of sketching capability by increasing confidence which can have a positive impact on the generation of design ideas.

KEYWORDS: Digital sketching, industrial design, product design, tablet PC, drawing

\section{Introduction}

With three dimensional (3D) Computer Aided Design (CAD) now established in professional industrial/product design practice and education, the use of computers has been extended to two dimensional (2D) digital sketching through the use of line, shade and colour using freehand-techniques. The basic techniques of $2 \mathrm{D}$ visualisation have their origins with the emergence of the industrial design profession and have now been adapted for computerbased sketching through the use of pen tablets/displays and drawing software.

Whilst parallels exist in the basic sketching skills required to effectively employ digital or paper-based techniques, in the context of design practice and the inherent differences between the two media, contrasting strengths and weaknesses are inevitable. For example, 
using a stand-alone computer and pen tablet/display for digital sketching has a negative impact on portability and spontaneity when compared to paper-based techniques. In contrast, by operating outside of the digital environment, paper-based techniques cannot exploit the capability to make immediate alterations (Marx, 2000; Dorta et al, 2008; Lee, 2006) or efficiently trace 2D sketches into 3D CAD.

With the emergence of the compact, portable tablet PC that enables sketching via a direct pen display and the transition of $2 \mathrm{D}$ sketches to $3 \mathrm{D}$ geometry using industry-standard CAD software, there is the potential to move towards a fully mobile design studio that represents a paradigm shift in the academic learning environment as contentiously alluded to by Malins et al: "The traditional studio-based model of design education is in the process of being replaced by a laptop on the kitchen table." (Malins et al, 2007). Acknowledging the significance of sketching to industrial/product design activity, in an absence of related studies that focus on capable practice-related activity, the aim of this study was to compare and contrast design sketching using the tablet PC with paper-based methods. The focus of the study was on industrial/product design, but the generic nature of sketching makes the findings of relevance to academic researchers, design educators and practitioners in a range of visually creative design disciplines. Specific aims of the research were:

1. To undertake a period of familiarisation in the use of the digital design sketching before the commencement of data collection

2. To employ focused sketching tasks under controlled conditions to facilitate data collection on capability, strategy and attributes when using paper-based sketching and digital sketching

3. To obtain expert opinion on the effectiveness of participants' outcomes in using paperbased sketching and digital sketching

4. To employ a focused design tasks under controlled conditions to facilitate data collection on the contribution of digital sketching to concept generation

5. To identify key issues relating to digital industrial/product design sketching after a period of extended use

\section{Design Sketching}

The significant contribution of sketching to the externalization and transformation of ideas during visually creative design practice is acknowledged (Schon and Wiggins, 1992; Lawson 
2006) and is effectively summarised as "the formation of images that provide a starting point related to a possible physical form and a way of developing that form" (Purcell and Gero, 1998). At the start of design activity, sketching needs to be spontaneous and contain limited detail (Henry, 2012). Pipes refers to this activity as 'concept sketching' and sees it as analogous to the designer "thinking aloud with a pencil" (Pipes, 1990).

Speed and spontaneity are central to effective sketching, with key elements being line, shade and colour Tovey et al 2003). Tovey et al. (ibid) note that the use of line is the most important aspect of sketching, with shading and colour being employed as the design become more refined. Media used by industrial/product designers vary according to personal preference but, when using paper-based techniques, pencils and fine-line pens represent the most flexible and durable media for concept generation (Powell, 1990. Differences between sketches and drawings have been identified, with sketches being spontaneous freehand visualisations of initial ideas whilst drawings involve greater control in the representations of objects that already exist (Tovey et al, 2003; Archer, 1992; Ullman et al, 1990; Evans and Pei, 2011). A variety of sketches can be employed during industrial/product design activity, with 8 distinctive types being identified by Pei et al (2011), all of which have the capacity to be produced using paper-based or digital techniques. Johnson (2005) and Aldoy \& Evans (2011) note the continued significance of visualisation using 2D sketching to design education and practice in the visually creative design disciplines.

The evolution of design proposals via concept generation has been explored by Edmonds and Soufi (1996) who identify 'emergence' whereby the uncertainty and ambiguity of the sketch performs a key role in the production of further ideas. This inherent ambiguity differs from the precise, mathematically driven modelling methods of 3D CAD, although the term 'sketching' has also been applied by researchers to refer to the conceptual phase of design activity that employs 3D CAD (Bilda and Demirkan, 2003), but this is not typical.

Two forms of hardware have been identified to facilitate digital sketching. The use of a stylus with a drawing tablet that is positioned to the side of the keyboard in which sketching appears on a standard monitor display is defined by Lee and Wei (2007) as "indirect interaction", with Aldoy calling the device a "digitising tablet without built-in display" (2011). When the drawing tablet is integrated into the screen display so that sketching takes place on the display surface in a process that more closely follows paper-based sketching, this is described as 'direct interaction' by Lee and Wei (2007) and a 'digitising tablet with interactive display' by Aldoy (2011). As a key manufacturer of hardware to support digital sketching, the Wacom 
Corporation describe their products for indirect interaction as 'pen tablets' and those for direct interaction as 'pen displays' (Wacom: 2014). The nomenclature used for this research employs a combination of the Wacom (2014) and Lee and Wei (2007) definitions, i.e. 'indirect pen tablet' and 'direct pen display'. When using an indirect pen tablet, the movement of the mark-making stylus is away from the display and, with a direct pen display, the stylus is used directly on the screen.

In a study on the interaction between junior and senior industrial designers when using digital sketching and paper-based techniques (sample size four), Lee and Wei (2007) noted that the direct pen display provided greater control over hand movement during collaboration when compared with conventional paper-based techniques. Faber (2009) sought feedback from 25 art and design students (excluding industrial/product design) on the use of indirect pen tablets during the development of digital sketching capability although it was not possible to draw conclusions on the significance of the findings as statistics for responses to the ten questions were not provided. Tang et al. (2011) explored collaborative interaction during colocation plus interaction using a remote environment via a collaborative design competition, with pairs of industrial design students using direct pen displays in separate rooms plus a face to face sketching environment that used paper-based techniques. The 60 minute design exercises (two of 30 minutes duration for each media) employed 10 pairs of third year students (total 20 subjects) but research into the capabilities of digital and paper-based sketching to support core industrial design activity was out of the scope of the study. When the design outcomes were assessed by experts, the overall score given to the designs produced using the paper-based media was slightly higher than the ones created using digital techniques (ibid). The findings noted that "the design process of the digital and traditional environments were similar in terms of the speed of the design process" (ibid) but the design task was relatively simple, short-term and had outcomes that were unrefined sketches (ibid).

This study addresses a gap in knowledge relating to the use of a direct pen display for capable digital sketching during industrial/product design activity.

\section{Methodology}

The significance of portability and immediacy when using creative paper-based sketchbooks has been identified by O'Neill (2013) and the relatively compact tablet PC has the capacity to emulate this through the use of an in-built direct pen display. Digital sketching can be 
undertaken on the tablet PC with industry standard software and, when necessary, orthographic views of designs traced into 3D CAD. This reproduces the key capabilities of studio-located systems that employ a stand-alone PC with full-size direct pen display such as the Wacom Cintiq (Wacom: 2014). As a device with the capacity to emulate the portability of paper-based sketching, the tablet PC was selected to compare and contrast digital sketching with paper-based methods.

In contrast to studies that explored different aspects of digital sketching through short-term design tasks (Lee and Wei, 2007; Bilda and Demirkan, 2003; Tang et al, 2011), the methodology for this study sought in-depth insights that could only be generated through long-term and sustained use of the tablet PC. This was achieved by employing a qualitative longitudinal study in which 16 participants had unlimited use of a new and fully supported Hewlett Packard EliteBook 2730p tablet PC using a Windows XP operating system for 9 months. This device had a $307 \mathrm{~mm}$ swiveling direct pen display and integral stylus. Questionnaires and focus groups took place in months 4, 5 and 9 of the study to collect qualitative data that Miles and Huberman (1994) describe as, "a source of well grounded, rich descriptions and explanations for processes in identifiable local contexts". The participants were final year undergraduate industrial/product design students at Loughborough Design School who had responded to an invitation to take part in the study. Each participant was provided with a tablet PC for the duration of the project that was fully supported by a university technician and had Microsoft Office software and industry standard packages to support digital sketching (Adobe Photoshop/lllustrator, Autodesk Sketchbook Pro) and 3D CAD (Pro-Engineer/Creo). Sketching was undertaken with the tablet PC's integral pen stylus which had a close association with a conventional pen/pencil used for paper-based sketching. To ensure that the functionality of the tablet PC was being effectively employed, two months after the commencement of the project, a Shared Experience Session was devised to review ways in which the tablet PC was being used and provide support from both researchers and participants to help resolve any problems.

After four months of use for project work that included concept generation and development for a major project, data collection comprised three activities. These involved a sketching exercise followed by a questionnaire to explore the contrasting experience of using paperbased techniques and the tablet PC. This was followed by an expert opinion questionnaire to identify which of the two media produced the most effective outcome. A design exercise and questionnaire was used to identify the strengths and weaknesses of using the tablet PC. 
After five months of use and increasing familiarisation/competence, a focus group was devised to identify the broadest range of issues relating to the two media. The significance of these issues would then become apparent after nine months use through the a designing questionnaire by presenting the comments from the focus group as statements that required Likert scale responses to identify the level of agreement or disagreement. The approach to data collection was to use contrasting methods to facilitate triangulation thereby "converging several sources of data or perspectives from participants adding validity of the study" (Cresswell, 2009). The methodology is outlined in Table 1.

\section{Table 1 Research Methodology}

\begin{tabular}{|c|c|}
\hline Month & Activity \\
\hline 0 & $\begin{array}{ll}\text { - } & \text { Invitation to participate in data collection (e-mail) } \\
\text { - } & \text { Selected participants informed (e-mail) } \\
\text { - } & \text { Briefing and distribution of } 16 \text { tablet PCs/software }\end{array}$ \\
\hline 2 & - $\quad$ Shared Experience Session \\
\hline 4 & $\begin{array}{l}\text { - Sketching \& Design Exercises } \\
\text { - Sketching Exercise } \\
\text { - Sketching Exercise Questionnaire } \\
\text { - Expert Opinion on Sketched Outcomes Questionnaire } \\
\text { - Design Exercise } \\
\text { - Design Exercise Questionnaire }\end{array}$ \\
\hline 5 & $\begin{array}{l}\text { Identification of Key Issues } \\
\text { - Focus Group }\end{array}$ \\
\hline 9 & $\begin{array}{l}\text { - Use of Tablet PC for Designing } \\
\text { - Questionnaire } \\
\text { - } \quad \text { Return of tablet PCs }\end{array}$ \\
\hline
\end{tabular}

\section{Shared Experience Session (Month 2)}

The Shared Experience Session was devised to promote effective use by allowing participants to discuss the capabilities of the tablet PC and share experience/advice. In addition to the general discussion that was initiated by the researchers, participants were asked to present an example of digital sketching for concept generation that had been undertaken with the tablet PC during the early stages of their final year major project.

Informal discussions during the session indicated that the tablet PC was well received and there was a consensus that it was making a positive contribution to design activity. This session reiterated the option to withdraw from the study but all participants expressed a desire to continue to participate for the remaining seven months. Examples of design work presented during the session indicated that the tablet PC was being effectively employed for design activity at an appropriate level for final year students. Examples of concept generation using line and colour for two of the participants can be seen in Figures 1 and 2. 


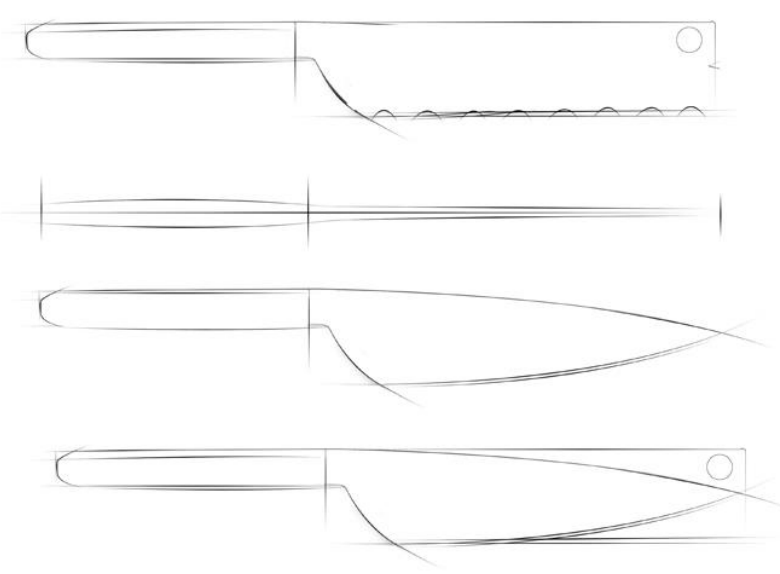

Figure 1 Elevational digital sketches for knife designs in line only

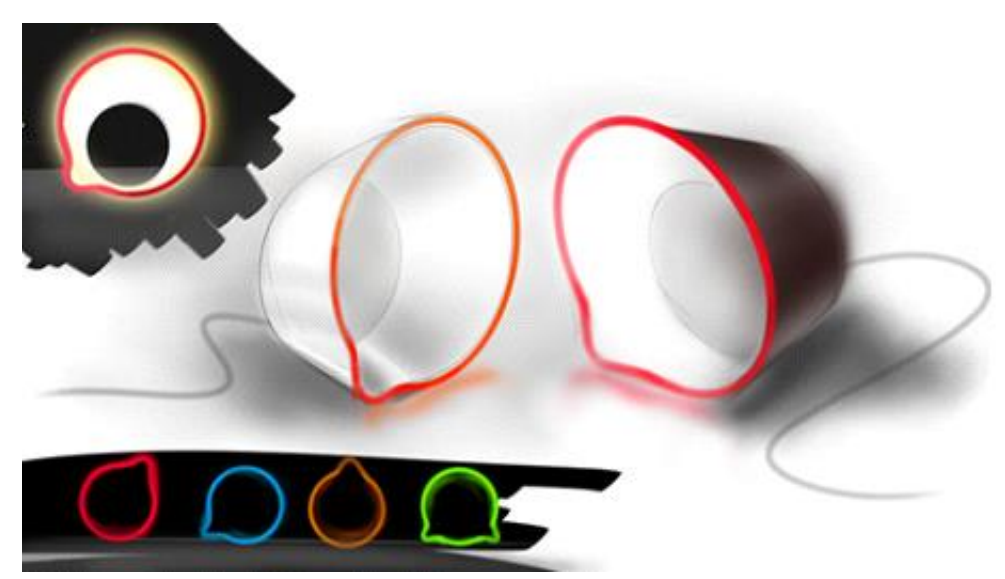

Figure 2 Perspective digital sketches for portable lighting using line and colour

Whilst it was beyond the scope of the study to explore ways in which participants were employing the tablet PC to transition between digital sketching and 3D CAD, informal comments indicated that this joint functionality was an essential component in the approach for a 'mobile design studio' and was being fully utilised.

\section{Sketching \& Design Exercises (Month Four)}

\section{Sketching Exercise}

After using the tablet PC for four months, data was collected to compare and contrast attitudes towards paper-based sketching and digital sketching. To encourage reflection on the attributes of the two media and provide material for subsequent expert opinion on the 
effectiveness of the sketches, participants were required to sketch two products using paperbased techniques and the same products using the tablet PC during a controlled exercise.

During concept generation using a perspective sketching technique, the nature of product form generally determines the sketching techniques employed, with crating and ellipses used for primitive geometry and contour lines and bulkheads for those with freeform curvature (Henry, 2012; Eissen \& Steur, 2007). As such, industrial/product designers develop approaches to sketching that are based on these core principles although nuances in personal style inevitably vary.

For the Sketching Exercise, objects were selected that required each of the two techniques to be used as there was the potential for either paper-based sketching or the tablet PC to be more suited to one or the other. The two objects used for the exercise were carefully selected so that they would require the use of the two approaches to sketching. These were a classic torch design that was based on primitive geometric forms (see Figure 3) and a toddler's spoon based on freeform curvature (see Figure 4).

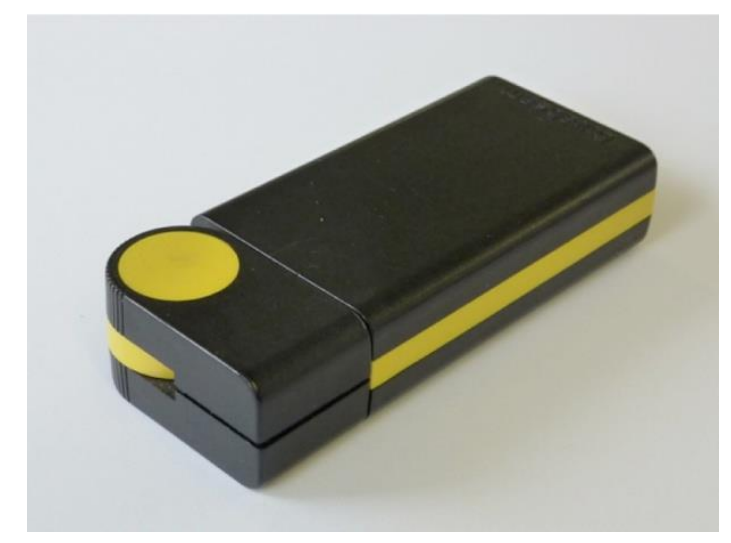

Figure 3 Geometric shaped torch used for sketching exercise

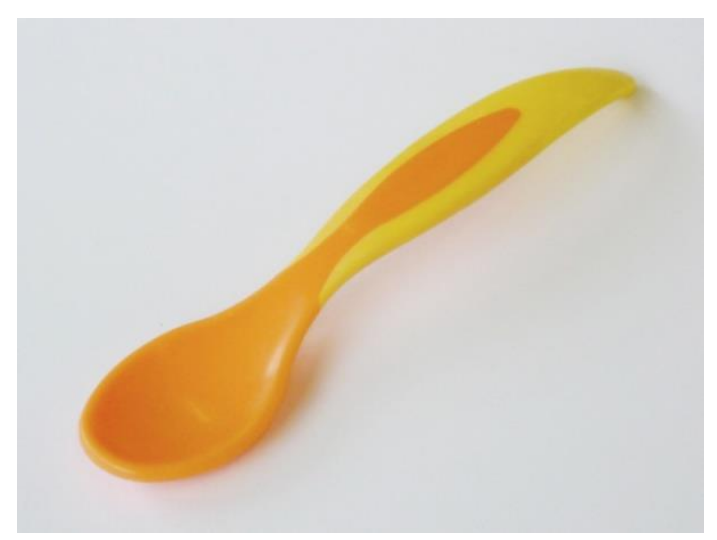

Figure 4 Organic shaped child's spoon used for sketching exercise 
The Sketching Exercise required the production of two sketches for the torch (one using paper-based techniques and one using the tablet PC) plus two sketches for the child's spoon (one using paper-based techniques and one using the tablet PC). Sketching was from observation using the physical products (not photographs) and their orientation was fixed to prevent bias due to participants selecting easier or more challenging viewing angles. As finalist industrial/product design students who had received a significant amount of sketching tuition, the 3D form of the objects was considered as being relatively straightforward and five minutes was allowed to complete each individual sketch (total 20 minutes of sketching activity). The sequence of the object selected to be sketched first (torch or spoon) and media used (paper and tablet PC) was randomised to avoid order effects.

Fifteen out of the 16 participants who signed-up for the case study took part in the Sketching Exercise as one was ill on the day. Examples of the four sketches produced by one of the participants using the two different media to sketch the child's spoon and torch can be seen in Figures 5-8.

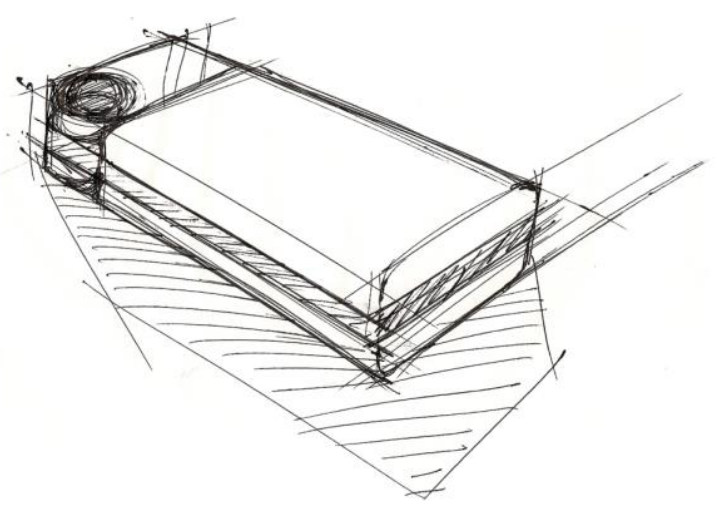

Figure 5 Participant 2 sketch of the torch using paper-based media

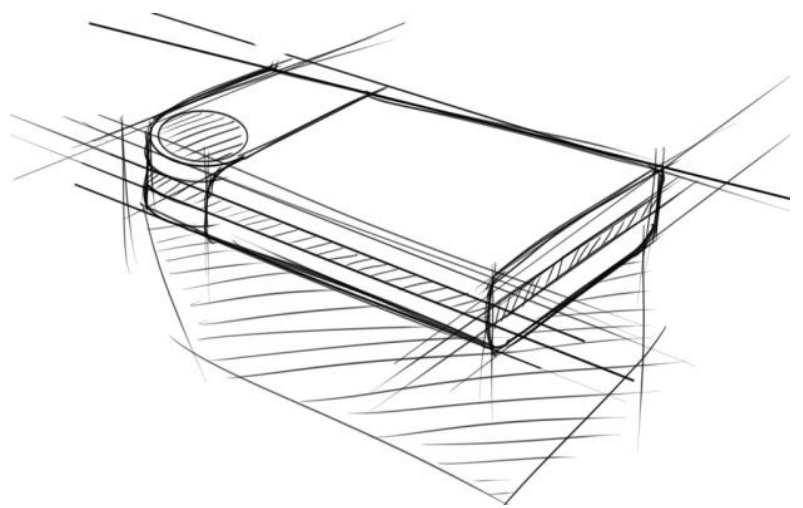

Figure 6 Participant 2 sketch of the torch using the tablet PC 


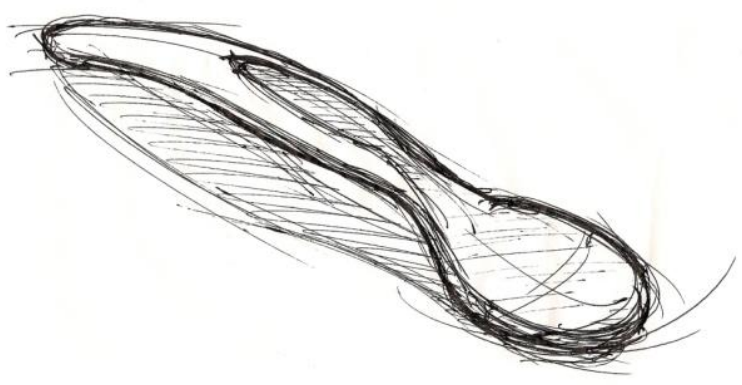

Figure 7 Participant 2 sketch of the child's spoon using paper-based media

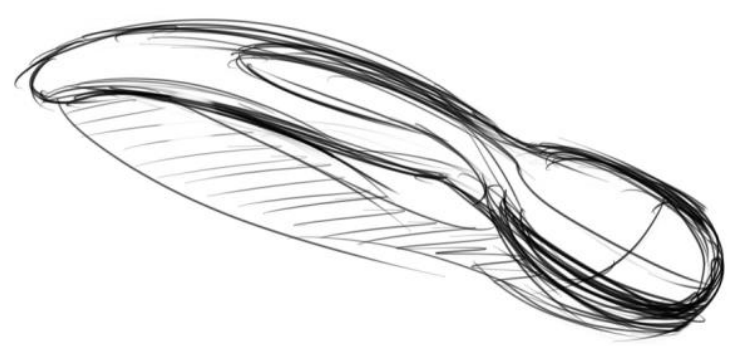

Figure 8 Participant 2 sketch of the child's spoon using the tablet PC

\section{Sketching Exercise Questionnaire}

On completion of the four exercises, participants were asked to complete a Sketching Exercise Questionnaire that explored capability, strategies and attributes of paper-based sketching and digital sketching using the tablet PC. The questionnaire consisted of three sections. The aim of the first section was to identify if the participant felt that they were more capable at sketching with paper-based techniques or the tablet PC. This used five-point Likert scale responses with the option of a mid-point that identifies the perception of capability with greater accuracy (Edwards \& Talbot, 1999). The aim of the second section was to identify differences in product sketching strategies when using paper-based techniques and those for the tablet PC. This required the listing of up to five differences as open-ended responses in a rank order list (most significant first). The final section sought opinion on practical and emotional attributes of paper-based sketching and using the tablet PC. This required an indication of which media was most relevant to eight statements relating to accuracy, confidence, expression, enjoyment, speed, ease, need for corrections and preferred outcome. 
As the aim of the study was to identify how sketching with the tablet PC compared to that of paper-based techniques, there was an opportunity to identify any enhancement to output and capability afforded by the digital media. Participants were given questionnaire statements on the "Most accurate representation of product" (Question 3.1) and "Preferred final sketch" (Question 3.8) which related to the credibility of the outcomes as industrial/product design sketches using both products/media.

When participants were asked to rate their sketching ability using the two media in Section 1 of the questionnaire, the results indicated that the majority of participants felt neutral about using the tablet PC (rated at 3), while seven felt more confident using paper-based techniques (rated at 4) as opposed to two using the tablet PC (see Figure 9).

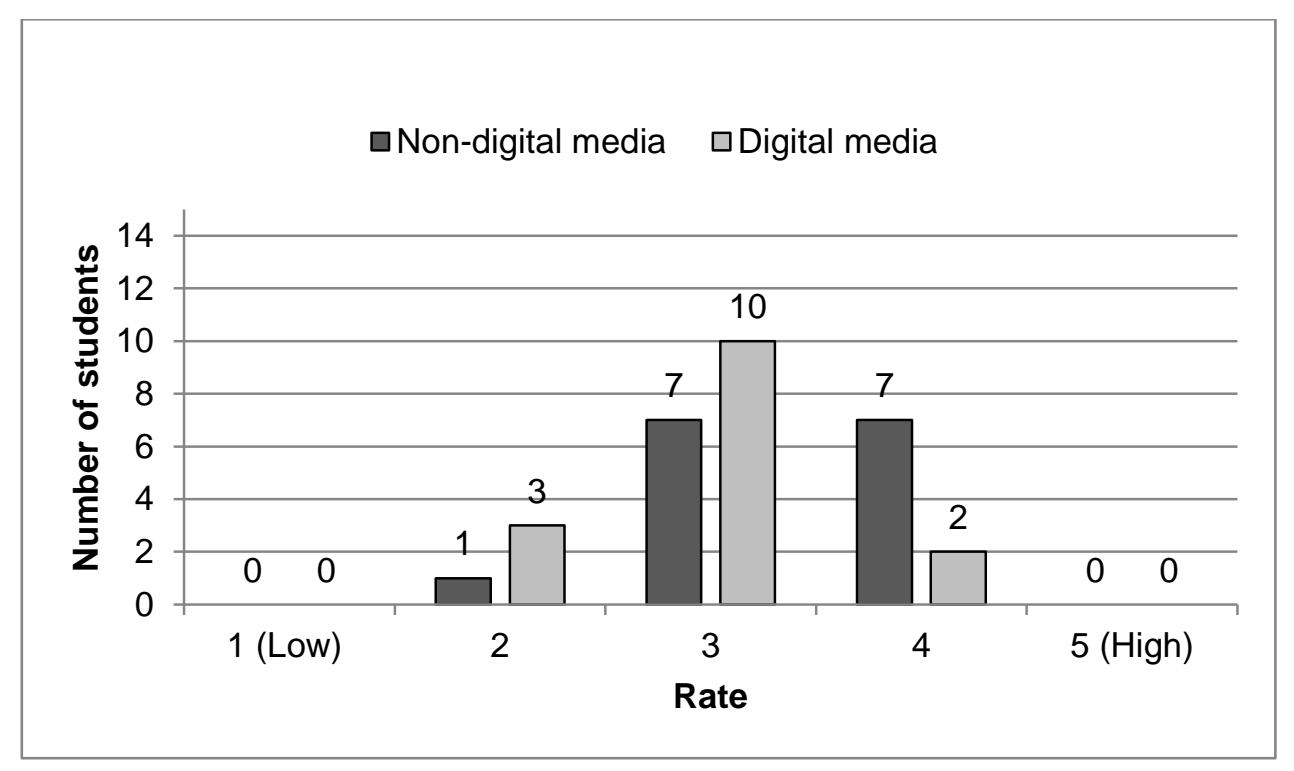

Figure 9 Student responses to Question 1: "How would you rate your ability to sketch using line only during design activity with the following media (1 being low and 5 being high)?" $n=15$

Question 2 was open-ended and asked: "How did the sketching strategies differ between non-digital and digital media? Please list them in rank order with the most significant difference first". Responses to this question were analysed using NVivo 9 software with findings indicating that the ease of using the layers function with the tablet PC was the most important feature. The use of layers can be seen as a digital version of underlays (i.e. sketching on a new sheet of paper whilst using previous work as a guide) which is typical of practice when using paper-based techniques. Whilst some participants believed that they had greater control of line, weight and flow when using paper-based techniques, it was felt that the tablet PC increased the use of spontaneous experimental shading. Some participants 
noted the ease with which they could create perfect lines and apply colour using the tablet PC when compared to paper-based techniques.

Question 3 required participants to indicate which of eight statements were most relevant to paper-based (non-digital) sketching, digital sketching (tablet PC) or equally to both. The questions focused on quality of outcome, (questions 1, 8), emotional response (questions 2, 3,4 ) and effectiveness (questions 5, 6, 7). The results indicated that paper-based sketching facilitated the "Most accurate representation of a product"; "Most confidence in use of line"; was "Quickest to produce"; and "Easiest to use". In contrast, digital techniques using the tablet PC "Required most error corrections" and produced the "Preferred final sketch". The latter response was in contrast to the findings of Tang et al's (2011) study on collaboration using digital techniques which identified the paper-based sketch as the preferred outcome. Areas where differences between paper-based techniques and the tablet PC were less pronounced (difference of 2 or less responses) related to the media being "expressive" and "enjoyable".

In terms of the quality of sketched outcome, there was a degree of ambiguity. For Question 3.1 ("Most accurate representation of product"), paper-based sketches received the highest score (9 responses) compared to the tablet pc (4 responses), but for Question 3.8 ("Preferred final sketch"), the tablet PC received the highest score (8 responses) compared to paperbased techniques ( 5 responses). From the perspective of the student participants who had undertaken the Sketching Exercise, there appeared to be confusion as to which media produced the most effective sketch.

Table 2 provides a breakdown of all responses for the Sketching Exercise Questionnaire questions 1 and 3. 
Table 2 Responses for Sketching Exercise Questions 1 and 3 ( $n=15)$

\begin{tabular}{|c|c|c|c|c|c|c|}
\hline \multicolumn{2}{|r|}{ QUESTION } & \multicolumn{5}{|c|}{ RESPONSE } \\
\hline 1 & $\begin{array}{l}\text { How would you rate your ability to sketch using line } \\
\text { only during the design activity with the following } \\
\text { media ( } 1 \text { being low and } 5 \text { being high)? }\end{array}$ & $\begin{array}{c}1 \\
\text { (Low) }\end{array}$ & 2 & 3 & 4 & $\begin{array}{c}5 \\
\text { (High) }\end{array}$ \\
\hline 1 & Non-digital media & 0 & 1 & 7 & 7 & 0 \\
\hline 2 & Digital media & 0 & 3 & 10 & 2 & 0 \\
\hline \multicolumn{2}{|r|}{ QUESTION } & \multicolumn{5}{|c|}{ RESPONSE } \\
\hline 3 & $\begin{array}{l}\text { Indicate which of the following statements applies most } \\
\text { to either your non-digital sketching; your digital } \\
\text { sketching; or equally to both. }\end{array}$ & \multicolumn{2}{|c|}{$\begin{array}{l}\text { Non-digital } \\
\text { sketching }\end{array}$} & $\begin{array}{c}\text { Digital } \\
\text { sketching }\end{array}$ & & $\begin{array}{l}\text { tal and } \\
\text {-digital } \\
\text { tching }\end{array}$ \\
\hline 1 & Most accurate representation of product & \multicolumn{2}{|c|}{9} & 4 & & 2 \\
\hline 2 & Most confidence in use of line & \multicolumn{2}{|c|}{11} & 3 & & 1 \\
\hline 3 & Most expressive & \multicolumn{2}{|c|}{7} & 6 & & 2 \\
\hline 4 & Most enjoyable & \multicolumn{2}{|c|}{6} & 8 & & 1 \\
\hline 5 & Quickest to produce & \multicolumn{2}{|c|}{11} & 3 & & 1 \\
\hline 6 & Easiest to use & \multicolumn{2}{|c|}{11} & 2 & & 2 \\
\hline 7 & Required most error corrections (erase/undo) & \multicolumn{2}{|c|}{4} & 10 & & 1 \\
\hline 8 & Preferred final sketch & \multicolumn{2}{|c|}{5} & 8 & & 2 \\
\hline
\end{tabular}

\section{Expert Opinion on Sketched Outcomes Questionnaire}

The student participants had an awareness of the characteristics for effective sketching but expert opinion was included within the methodology to provide further evidence on which media produced the most credible result. The Expert Opinion on Sketched Outcomes Questionnaire was devised to identify if students had produced the most effective sketches using the tablet PC or paper-based techniques. The questionnaire utilised the four sketches per student that were produced using the tablet PC and paper-based techniques for the spoon and torch. Two sketches for each product were used to create A4 questionnaires that included tick boxes to enable the expert to indicate which most effectively represented product form or if a difference could not be distinguished. The experts were provided with photographs of the torch and spoon to ensure that they understood the product form that had been sketched. The questionnaire was completed by 12 academic staff who were qualified industrial designers with a minimum of 10 years commercial experience and had taught sketching to undergraduate students.

With no clear consensus from the participants Sketching Exercise Questionnaire as to whether paper-based or digital sketching was achieving the most credible result (Figure 9), the Expert Opinion Questionnaire provided an additional level of appraisal. On completion, a clear preference was given for the paper-based non-digital sketches in the effective communication of product form, with $49.4 \%$ for the torch and $51.9 \%$ for the spoon. This 
contrasted with the results for the digital methods of the tablet PC at $26.3 \%$ for the torch and $24.4 \%$ for the spoon (see Figure 10 ).

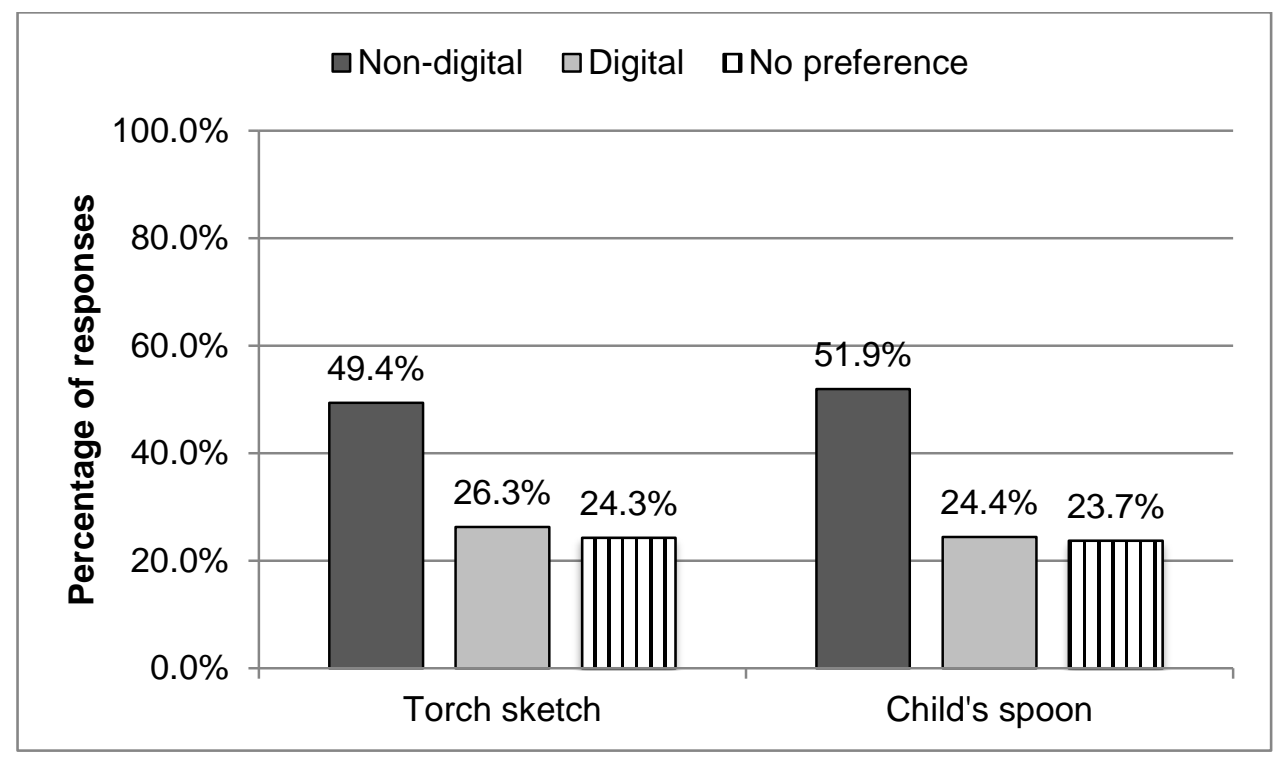

Figure 10 Graph showing the average (mean) percentage of academics in response to Question: "Please indicate which sketch is most effective in the communication of product form" $n=12$

\section{Design Exercise}

Whilst participants had been using the tablet PC for four months of design activity during their final year of studies, this was not under controlled conditions and timescales to complete tasks varied from one to four months. To identify the contribution of the tablet PC for concept generation through sketching, a two hour design exercise was devised that simulated the demands of commercial practice under time constraint. This involved the design of a pepper mill for which participants were given a detailed briefing supported by images for a diverse range of existing design solutions. By the end of the session, participants were required to present a sketched design proposal that included a single perspective view plus two orthographic views. The application of colour/shade was optional and the use of 3D CAD software was not allowed as the focus of activity was spontaneous digital sketching for concept generation. The design exercise enabled use of the full functionality of the tablet PC's interactive display and capacity to sketch using line, tone and colour as seen Figure 11. 


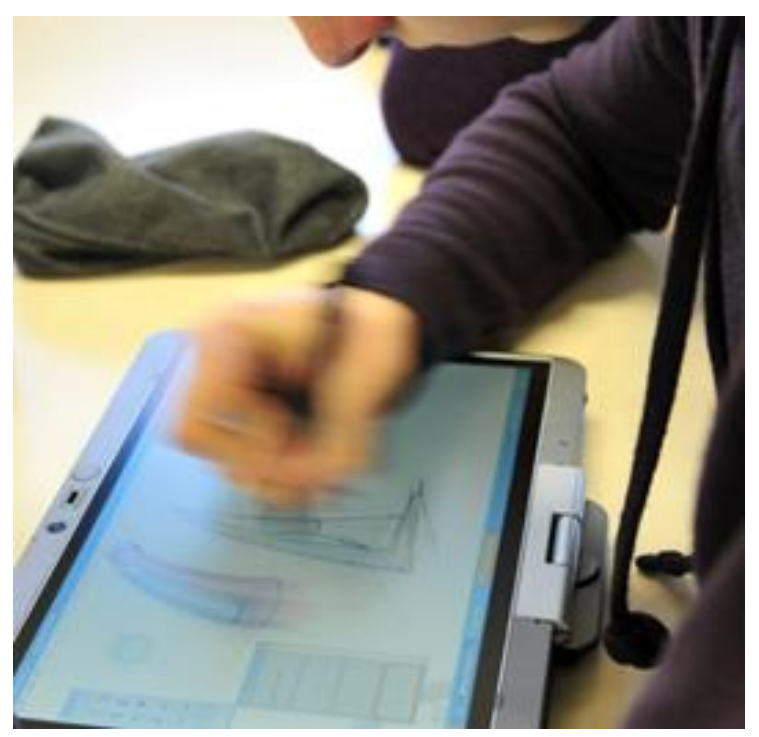

Figure 11 Loose application of colour whilst sketching pepper mill concepts

During the Design Exercise, it was noted that participants would switch between design sketching and accessing supporting material on the internet. Such activity would still be possible when using a combination of paper-based techniques plus an internet enabled computer, but it was apparent that the tablet PC facilitated a seamless transition between sketching and access to on-line images to support design activity. This went beyond the more typical searches for examples of related products and stylistic direction as was the case with the proposal illustrated in Figure 12 that involved accessing an image of hands in the pose required for the visualization of the concept. This was imported into image manipulation software (Adobe Photoshop) and traced using the tablet PC stylus for use in the final proposal. In producing the proposal illustrated in Figure 13, internet access to open-access typefaces enable a suitable font to be downloaded, modified and then integrated within the digital sketch.
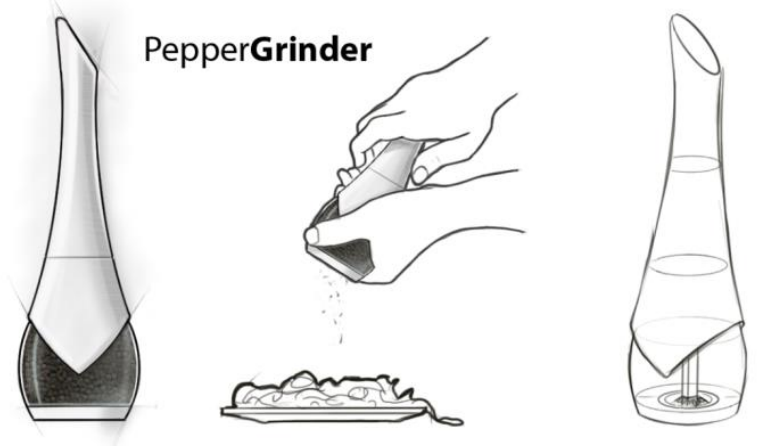

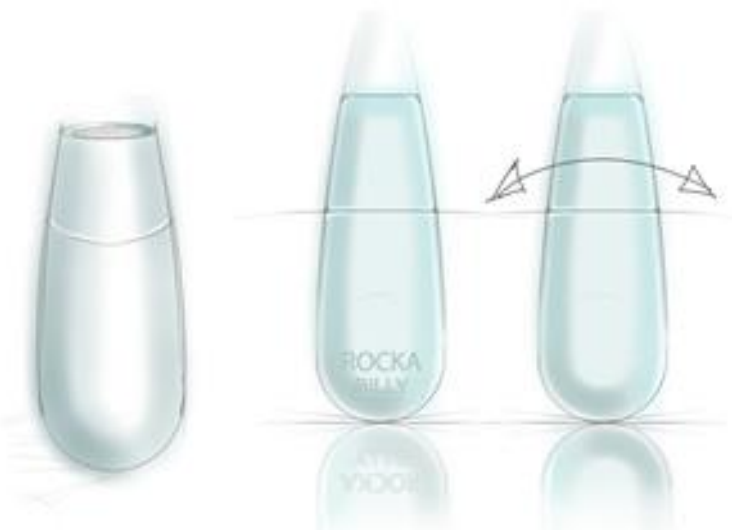

Figure 13 Example of sketch rendering using downloaded typography

\section{Design Exercise Questionnaire}

On completion of the Design Exercise, participants were asked to complete an open-ended questionnaire that required the rank order listing of three strengths and three weaknesses in using the tablet PC for concept generation. Collation of the data revealed that the ability to undo mistakes was the most significant advantage (9 occurrences). This contribution to sketched output was underpinned by the ability to quickly render and shade (7 occurrences). The most significant weakness was precision of the pen stylus ( 9 occurrences) caused by the thickness of the screen and calibration of the pen tool. Participants also identified shortcomings with the relatively small screen ( 6 occurrences) and problems with glare ( 5 occurrences). A key feature of the weaknesses was that 12 out of the 17 related to design features of the tablet PC (e.g. calibration of stylus tool, size of screen, screen glare, height of tablet, lack of friction on sketching surface) as opposed to 2 that related to software (pop-ups, undoing) and 3 that were a combination of the 2 (slows down sketching, constrictive, takes a while to get used to). Table 3 provides a summary of the responses for strengths and weaknesses. 
Table 3 Summary of the tablet PC strengths and weakness identified by participants on completion of the Design Exercise $(n=15)$

\begin{tabular}{|lc|lc|}
\hline \multicolumn{1}{|c|}{ Strengths } & Occurrences & \multicolumn{1}{c|}{ Weaknesses } & Occurrences \\
\hline Ability to undo & 9 & Poor calibration of the stylus tool & 9 \\
Quick rendering and shading & 7 & Size of the screen & 6 \\
Layers advantage & 5 & Screen glare & 5 \\
Variety of tools to hand & 5 & Difficult to rotate screen & 4 \\
Easy access & 3 & Height of tablet & 4 \\
Producing slight variation quickly & 3 & Lack of friction & 3 \\
Ease of creating straight & 3 & $\begin{array}{l}\text { Keyboard unusable when } \\
\text { sketching }\end{array}$ & 2 \\
lines/shapes & 2 & Slows down sketching & 2 \\
Quality of rending & 2 & Not good without a mouse & 1 \\
Outcome looks good & 1 & Stylus does not feel like a pen & 1 \\
Pressure sensitive & 1 & Difficult to compare a range of & 1 \\
Ability to change size and & ideas & 1 \\
orientation & 1 & Pop-ups disturbs workflow & 1 \\
Sketching & 1 & Screen at an uncomfortable angle & 1 \\
Smoothness of line & Easy to 'slip' on small details & 1 \\
& & Encourages undoing & 1 \\
& & Constrictive & \\
& & Takes a while to get used to & 1 \\
\hline
\end{tabular}

\section{Identification of Key Issues (Month 5)}

\section{Focus Group}

After using the tablet PC for five months, the aim of the Key Issues Focus Group was to identify the breadth of issues relating to industrial/product design sketching with the tablet PC. These could then be used to create the Use of Tablet PC for Designing Questionnaire to be employed for the final data collection event in the final ninth month.

Two focus groups of eight students each (total 16) were moderated by the first author who had 20 years of experience in professional industrial design practice, teaching product sketching and research into digital design methods. The moderator ensured that all participants had equal voice and prevented forceful personalities from dominating discussions (Robson, 2002). The second author supported the activity and took responsibility for audio recording and transcription. Six statements drove the focus group discussions which centred on comparisons between the digital and non-digital media; impact on creativity; impact on productivity; skills required for effective use of the tablet PC; benefits of all design students having a tablet PC; and any other issues.

After transcription and use of Nvivo 9 data analysis software, seventy two distinctive responses were identified. Data reduction was undertaken through a process of coding and 
clustering (Cresswell, 2009; Miles \& Huberman, 1994) to establish which of the 72 issues were of significance. The clustering resulted in seven categories of response which were Quality of Outcome (enhancement/degradation in design representations); Pedagogy (implications for learning and teaching); Technique (references to specific tasks); Mobility (use beyond the main studio environment); Emotion (expression of feelings during use); Hardware (functionality of the tablet PC); and Software (functionality of sketching software when used on the tablet PC). The outcomes from the Key Issues Focus Group were then integrated into the Use of Tablet PC Questionnaire.

\section{Use of Tablet PC for Designing (Month 9)}

\section{Questionnaire}

After nine months of unlimited use to support the design of all final year undergraduate design projects, participants were asked to complete a Use of Tablet PC for Designing Questionnaire. The aim of this questionnaire was to generate insights into the capabilities of the tablet PC as a digital alternative to paper-based sketching and tool to support industrial design activity. The questionnaire was generated from the 72 issues that had been identified during the Key Issues Focus Group that took place in month 7. The questions were arranged randomly and all 16 participants completed the questionnaire.

When analysing the results, the most significant statements were identified as those that had received at least $80 \%$ of responses in the agree/strongly agree or disagree/strongly disagree category of the Likert scale. This resulted in 22 of the 72 statements receiving an agree/strongly agree response from 13 or more of the 16 participants as seen in Table 4 . 


\begin{tabular}{|c|c|c|c|c|c|c|c|}
\hline & QUESTION & & & RES & NSE & & \\
\hline$\frac{\bar{\Phi}}{\frac{\Phi}{D}}$ & $\begin{array}{l}\text { To what extent do you agree or disagree with the following } \\
\text { statements? }\end{array}$ & $\frac{\frac{0}{0}}{\frac{0}{0}} \frac{\frac{\mathrm{c}}{0}}{\frac{0}{0}}$ & 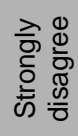 & 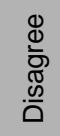 & 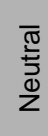 & $\frac{\Phi}{\frac{\Phi}{\square}}$ & 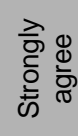 \\
\hline Q1 & $\begin{array}{l}\text { The line quality of the tablet PC was better than that for paper- } \\
\text { based sketching }\end{array}$ & 0 & 1 & 0 & 1 & 11 & 3 \\
\hline Q2 & $\begin{array}{l}\text { The quality of your renderings produced using computer } \\
\text { drawing packages (e.g. SketchBook Pro) improved using the } \\
\text { tablet PC }\end{array}$ & 0 & 0 & 0 & 1 & 8 & 7 \\
\hline P1 & $\begin{array}{l}\text { Students should be taught sketching using paper-based } \\
\text { techniques before using the tablet PC }\end{array}$ & 0 & 0 & 1 & 1 & 7 & 7 \\
\hline P2 & $\begin{array}{l}\text { Students should not be taught paper-based rendering } \\
\text { techniques as the tablet PC makes them redundant }\end{array}$ & 0 & 10 & 4 & 0 & 2 & 0 \\
\hline P3 & $\begin{array}{l}\text { Students should always have the option for using paper-based } \\
\text { techniques to sketch in addition to the tablet PC }\end{array}$ & 0 & 1 & 12 & 2 & 1 & 0 \\
\hline P4 & $\begin{array}{l}\text { Students need to be taught how to use the virtual keyboard on } \\
\text { the tablet PC desktop }\end{array}$ & 0 & 0 & 0 & 0 & 7 & 9 \\
\hline T1 & $\begin{array}{l}\text { It was easier to remove mistakes using the tablet PC than when } \\
\text { paper-based sketching }\end{array}$ & 0 & 0 & 0 & 0 & 7 & 9 \\
\hline T2 & $\begin{array}{l}\text { You were able to make quick amendments to your designs } \\
\text { using the tablet PC }\end{array}$ & 0 & 0 & 0 & 3 & 9 & 4 \\
\hline T3 & The tablet PC layering facility was very helpful & 0 & 0 & 0 & 1 & 5 & 10 \\
\hline $\mathrm{T} 4$ & $\begin{array}{l}\text { Applying colour and tone to your line work was quicker and } \\
\text { easier with the tablet PC }\end{array}$ & 0 & 0 & 1 & 2 & 6 & 7 \\
\hline T5 & $\begin{array}{l}\text { The tablet PC was easy to use for tracing and producing basic } \\
\text { outlines }\end{array}$ & 0 & 0 & 0 & 1 & 9 & 6 \\
\hline M1 & $\begin{array}{l}\text { If you had to work when visiting friends and family, you would } \\
\text { prefer to take the tablet PC rather than an A3 pad }\end{array}$ & 0 & 0 & 2 & 0 & 12 & 2 \\
\hline E1 & $\begin{array}{l}\text { You felt more confident using the tablet PC compared to paper- } \\
\text { based sketching because of the ability to 'undo' }\end{array}$ & 0 & 0 & 1 & 0 & 12 & 3 \\
\hline E2 & Using the tablet PC for designing introduced an element of fun & 0 & 0 & 2 & 1 & 13 & 0 \\
\hline E3 & $\begin{array}{l}\text { The tablet PC made you more adventurous when generating } \\
\text { concepts and developing them }\end{array}$ & 0 & 0 & 1 & 1 & 12 & 2 \\
\hline $\mathrm{H} 1$ & The tablet PC is pressure sensitive & 0 & 0 & 3 & 0 & 8 & 5 \\
\hline $\mathrm{H} 2$ & $\begin{array}{l}\text { After sketching for some time, you get used to the smoothness } \\
\text { of the tablet PC screen }\end{array}$ & 0 & 0 & 1 & 1 & 7 & 7 \\
\hline $\mathrm{H} 3$ & $\begin{array}{l}\text { The colours used on the tablet PC were more vibrant than those } \\
\text { available with paper-based techniques }\end{array}$ & 0 & 0 & 0 & 1 & 11 & 4 \\
\hline $\mathrm{H} 4$ & The battery life of the tablet PC was acceptable & 0 & 0 & 1 & 1 & 5 & 9 \\
\hline H5 & $\begin{array}{l}\text { The size of the tablet PC screen limited your ability to see } \\
\text { numerous previous ideas on the same page }\end{array}$ & 0 & 0 & 2 & 1 & 4 & 9 \\
\hline S1 & $\begin{array}{l}\text { SketchBook Pro was more suitable than Photoshop for the } \\
\text { generation of line work }\end{array}$ & 1 & 1 & 0 & 1 & 4 & 9 \\
\hline S2 & $\begin{array}{l}\text { SketchBook Pro was easier to use than Photoshop for the } \\
\text { generation of line work }\end{array}$ & 0 & 0 & 0 & 2 & 7 & 7 \\
\hline
\end{tabular}

In the Quality $(Q)$ cluster, when using the tablet PC there was enhancement to line-work (Q1) and rendering quality $(\mathrm{Q} 2)$. In the Pedagogy $(\mathrm{P})$ cluster, whilst there was a continuing need to teach paper-based sketching (P1) and rendering techniques (P2) with the option to use these as required (P3), there was no need to teach how to use the virtual keyboard on the tablet PC (P4). In the Technique (T) cluster, the tablet PC was effective when editing (T1, T2), using layers (T3), applying colour (T4) and tracing (T5). Only one statement related to Mobility (M1), indicating that the tablet PC was considered to be more portable than typical $A 3$ size paper. In the Emotion (E) cluster, when using the tablet $P C$ there was an increase in confidence (E1) and fun (E2) whilst making the students more adventurous when generating concepts (E3). In the Hardware $(\mathrm{H})$ cluster, the pressure sensitivity of the tablet PC was 
confirmed $(\mathrm{H} 1)$, smoothness of the screen (when compared with paper) overcome through use $(\mathrm{H} 2)$, colours were more vibrant compared to paper-based techniques $(\mathrm{H} 3)$ and battery life was acceptable $(\mathrm{H} 4)$. The size of the screen was considered as being a limiting factor in terms of the ability to view previous ideas (H5). In the Software cluster (S), Sketchbook Pro was considered as being more suitable (S1) and easier (S2) to use than Photoshop for the generation of line-work.

\section{Conclusions}

The study generated insights in the capacity of the tablet PC to support digital sketching during industrial/product design activity. The findings build on related previous studies by using a more focused, longitudinal approach that collected in-depth data over an extended time frame. It must be acknowledged that the study was conducted in a single design school and, as such, judgement must be made on the level to which generalization can be applied. However, it is the authors' belief that the sketching processes employed in the study are generic and applicable to mainstream industrial/product design education and practice.

Thanks to the enthusiastic contribution of final year students during what was a lengthy and at times demanding study, it was possible to fully meet the aims of the research as the participants had acquired the necessary level of capability to authoritatively respond to questions. Unlike studies into the use of digital sketching that had periods of familiarization measured in hours, the extended timeframe for this study of two months, plus the reflective group feedback session, proved particularly effective in consolidating previous learning before commencement of the main study (Aim 1). The methodology then built on increasing capability to facilitate the collection of robust data that supported Aim 2 (comparative paperbased/digital sketching), Aim 3 (expert feedback on Aim 2) and Aim 4 (design exercise). In answering Aim 5 (key issues relating to digital sketching), the results from this concluding questionnaire were authoritative not only because of the data collection activities that had built up to it but because the tablet PCs had been used for design activity that was above and beyond those directly related to the research project.

The Sketching Exercise Questionnaire indicated that whilst digital sketching using the tablet PC required more error corrections than paper-based techniques, it was apparent from responses to the Design Exercise Questionnaire that the ability to 'undo' was seen as the most significant strength. This was again confirmed in the Use of Tablet PC for Designing Questionnaire in which participants were in complete agreement that it was easier to remove 
mistakes during digital sketching (T1). The key impact of this during digital sketching was greater confidence (E1) and making designers more adventurous (E3). When combined with the perception that this also increased accuracy in the representation of product form, confidence in use of line, speed and ease of use (Sketching Exercise Questionnaire), a more complete picture of the contribution of the digital media becomes apparent. However, it must be acknowledge that despite these attributes, the Expert Opinion in Sketched Outcomes Questionnaire indicated that outcomes from paper-based sketching were more effective in the communication of product form. This positive attitude towards paper-based sketching over digital methods is reported by Aldoy and Evans (2011) which adds support to the use of a hybrid approach in which paper-based line-work is scanned and uploaded into a digital drawing package for further manipulation and the addition of colour. With a focus on standalone digital techniques, this hybrid approach was outside the scope of the study but this represents an area worthy of further study.

Deficiencies were identified in the hardware of the tablet PC such as precision of the pen stylus and glare. The calibration of the stylus tool along with the small screen size that prevented the viewing of other ideas at the same time were identified as weaknesses. This may explain why it was considered necessary to continue to teach paper-based sketching to undergraduate design students. Despite the advantages of the tablet PC, the majority of participants were in agreement that despite the allure of digital sketching, a place for paperbased techniques remains in practice and education.

Results from the Shared Experiences Session indicated the contribution to practice that was facilitated by the integration of digital sketching with 3D CAD in a single platform. Whilst sketching software is available for tablet PCs that use iOS and Android operating systems, these cannot currently employ the full functionality of industry standard 3D CAD software. This remains a short-coming for this popular platform as this study demonstrated the enhanced capability and effectiveness of Windows-based tablet PCs and capacity to move towards a fully integrated 'mobile design studio'.

\section{References}

Aldoy, N. (2011). An investigation into a digital strategy for industrial design education. PhD theses. Loughborough University

Aldoy, N and Evans, M. A. (2011). A review of digital industrial and product design methods in UK higher education. The Design Journal Volume 14 Issue 3, 343 - 361

Archer, B. (1992). As complex as ABC. In: Roberts, P., Archer, B. \& Baynes, K. (eds.) 
Modelling: The language of designing. Loughborough: Loughborough University

Bilda, Z. and Demirkan, H. (2003). An insight on designers' sketching activities versus digital media. Design Studies 24, 27 - 50

Cresswell, J. W. (2009) Research Design. Thousand Oaks California: Sage Publications Dorta, T. S., Perez, E. and Lesage, A. (2008). The ideation gap: hybrid tools, design flow and practice. Design Studies, 29, 121 - 141.

Edmonds, E.and Soufi, B. (1997). The cognitive basis of emergence: implications for design support. Design Studies 17, 451 - 463)

Edward, A and Talbot, R. (1999). The hard-pressed researcher: a research handbook for the caring professions, London, Longman.

Evans, M.A and Pei, E (2011) ID Cards. Accessed 26 September 2014 at

http://www.lboro.ac.uk/media/wwwlboroacuk/content/lds/downloads/research/researc hgroup

s/designpractice/IDSA\%20iD\%20Cards.pdf

Eissen and Steur (2007). Sketching: drawing techniques for product designers, Amsterdam: BIS.

Faber, C. H. (2009). Digital Drawing Tablet to Traditional Drawing on Paper: A Teaching Studio Comparison. Proceedings of the International Association of Societies of Design Research Conference 2009. Retrieved 16 March 2014 from: http://www.iasdr2009.org/ Henry, K. (2012). Drawing for Product Designers. London: Laurence King Johnson, B. (2005). Design ideation: the conceptual sketch in the digital age. Design Studies 26, $613-624$

Lawson, B. (2006) How designers think ( $4^{\text {th }}$ Edition). Oxford: Architectural Press Lee, B. (2006). From Cognitive artifacts to social artifacts: The ideas design ecology. User Interface Software and Technology (UIST) Confrence Montreux, Switzerland.

Lei, L-C and Wei, W-J (2007). Behaviour analysis between paper sketching and interactive pen display sketching in collaborative design. Proceeding of the $200711^{\text {th }}$ International Conference on Computer Supported Cooperative Work in Design. Melbourne: Australia, $304-308$

Malins, J., Pengelly, J., Marshall, J. (2007). The post disciplinary digital practitioner. In Bohemia, E., Hilton, K., McMahon, C., Proceedings of the International conference on engineering and product design education: shaping the future? Newcastle upon Tyne: Northumbria University

Marx, J. (2000). A proposal for alternatives methods for teaching digital design. Automation in Construction, 9, 19 - 35.

Miles, M. B. and Huberman, A. M. (1994). Qualitative Data Analysis. Thousand Oaks, 
California: Sage Publications

O'Neill, S. J. (2013) Re: thinking and designing a digital sketchbook. Digital Creativity Vol. 24, Issue 4, 291 - 309

Pei, E, Campbell, R. I., Evans, M.A. (2011) A taxonomic classification of visual design representations used by industrial designers and engineering designers. Design Journal Vol. 14, Issue 1, 64 - 91

Pipes, A. (1990) Drawing For Three Dimensional Design, New York: Thames \& Hudson

Powell, D. (1990) Presentation Techniques, London: Macdonald

Purcell, A. T. and Gero J. S. (1998) Drawings and the design process. Design Studies Vol. 19 No. 4, 389 - 430

Robson, C. (2002) Real world research. Oxford: Blackwell

Shon, D., and Wiggins, G. (1992) Kinds of seeing and their functions in designing. Design Studies Vol 3 No 2, $135-156$

Tang, H. H., Lee, Y. Y. and Gero, J. S (2011) Comparing collaborative colocated and distributed design processes in digital and traditional sketching environments: A protocol study using the function-behaviour-structure coding scheme. Design Studies 32, 1 - 19

Tovey, M., Porter, S. \& Newman, R. 2003. Sketching, concept development and automotive design. Design Studies, 24, 135-153.

Ullman, D. G., Wood, S. and Graig, D. (1990). The importance of drawing in the mechanical; design process. Computer \& Graphics, 14, 263-274.

Wacom 2014. Retrieved 16 May 2006 from: http://wacom.com/en/au/creative/cintiq-22-hd 